Robert J. Morrow BSc MD MRCOG, * Stephen H. Rolbin, MDCM FRCP, J.W. Knox Ritchie MD FRCOG FRCS, Susan Haley MD FRCP

\title{
Epidural anaesthesia and blood flow velocity in mother and fetus
}

Doppler ultrasound has recently been used to assess changes in blood velocity in the uterine and umbilical arteries. Alterations in the ratio of systolic to diastolic velocity (S/D ratio) are believed to reflect changes in placental vascular resistance. We have used this technique to assess potential beneficial or detrimental effects of epidural anaesthesia on blood flow to the placenta. Continuous wave Doppler ultrasound was used to measure the $S / D$ ratio in the uterine and umbilical arteries of 12 patients undergoing epidural anaesthesia prior to elective caesarean section. Anaesthesia was achieved using lidocaine and epinephrine. The SID ratio in both the uterine and umbilical arteries remained unaltered either by the fluid preload or by the epidural anaesthesia. It is concluded that epidural anaesthesia using this technique has neither a beneficial nor detrimental effect on uterine or umbilical blood velocity in the uncomplicated pregnancy.

\section{Key words}

ANAESTHESIA: obstetrical; MEASUREMENT: blood flow; PREGNANCY: caesarean section; UTERUS: blood flow.

From the Department of Obstetrical Perinatology* and Department of Anesthesia, Mount Sinai Hospital, University of Toronto Perinatal Complex, Toronto, Ontario.

RJM supported by The Hospital for Sick Children Foundation, Toronto, Ontario, Canada. Grant No. PMS-86-009.

Address correspondence to: R.J. Morrow, Department of Obstetrical Perinatology, Mount Sinaj Hospital, 600 University Avenue, Toronto, Ontario MSG 1X5.
Epidural anaesthesia is now commonly used for elective caesarean section. ${ }^{1}$ It has the advantage of allowing the mother to remain awake, minimizes the risk of maternal aspiration, and reduces drug effects on the newbom. Epidural anaesthesia causes autonomic nervous system blockade and may alter blood flow in the uteroplacental and umbilical vessels. ${ }^{2}$ Although the effects of epidural anaesthesia in labour are now well documented, it is not well established how blood flow is affected in the patient who is not in labour. Doppler ultrasound has recently been used to assess changes in blood velocity in these vessels. ${ }^{3-6}$ In this study, we assessed changes in blood velocity in the maternal and fetal circulations prior to elective caesarean section.

\section{Methods}

The uteroplacental and umbilical flow velocity waveforms (FVWs) were recorded in 12 women prior to elective repeat caesarean section. The patients were randomly selected from the normal obstetrical population and none had major obstetrical or medical complications. The study was approved by the hospital ethics committee and informed consent was obtained from each patient.

The velocity waveforms were obtained using a Doppler spectrum analyser with a $4 \mathrm{MHz}$ probe (Multigon, New York). The probe was applied to the maternal abdomen and signals characteristic of the uteroplacental and umbilical FVWs were obtained. ${ }^{4,6}$ The image was frozen and the ratio of the maximum systolic to minimum diastolic velocity (S/D) ratio was calculated with the aid of electronic calipers over at least five cardiac cycles. A permanent record was kept using a video printer (Mitsubishi, California). All measurements were made in the semi-left lateral position to avoid aorto-caval compression. The FVWs were recorded before "preloading" with intravenous fluid, after each $0.5 \mathrm{~L}$ of a $1.5 \mathrm{~L}$ "preload" and then every two minutes until 16 minutes after injection of the epidural anaesthetic. Anaesthesia was induced by the introduction of lidocaine two per cent and epinephrine $1: 200,000(20-30 \mathrm{ml})$ in the $\mathrm{L}_{3-4}$ interspace. The maternal ECG was continuously monitored and the blood pressure measured intermittently every 1-3 min using an automated cuff. The mean heart rate and blood pressure were calculated for each time period reported. 


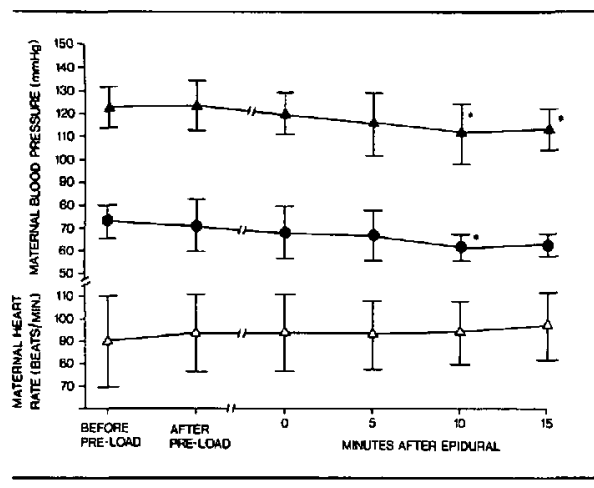

FIGURE 1 The effect of preload and epidural anaesthesia on maternal heart rate $(\Delta)$ and systolic $(\mathbf{\Lambda})$ and diastolic $(\boldsymbol{\bullet})$ blood pressure (mean \pm SD) $\left({ }^{*} P<0.05\right.$ compared with time 0$)$.

The infants were assessed by umbilical arterial and venous blood gas analyses, Apgar scores and a general examination were performed by a neonatologist.

An analysis of variance was used to assess statistical significance and results regarded as significant if $P<$ 0.05 . Values obtained during the preload were compared with control values taken immediately before the infusion. Values obtained during epidural anaesthesia were compared with control values taken following the preload and insertion of the epidural catheter but before the injection of local anaesthetic (time 0, Figures 1, 2, and 3).

Statistical tests were made of the null hypothesis that there was no change in the S/D ratio following "preload" or infusion of anaesthetic. Dunnett's procedure for multiple comparisons was used to reduce the possibility of type I error.

\section{Results}

The maternal blood pressure (Figure 1) did not alter significantly during the preload. Following the epidural anesthetic, both systolic and diastolic pressures were significantly reduced at ten minutes $(P<0.05$ ) (by 8 and $6 \mathrm{mmHg}$ respectively) and the systolic pressure remained reduced $(P<0.05$ ) at 15 minutes (by $6 \mathrm{mmHg}$ ). The matemal heart rate did not alter significantly throughout the study.

There were no significant changes in the S/D ratios in either the uteroplacental or umbilical circulations either during the fluid "preload," after insertion of the epidural catheter or after the epidural anaesthetic had been administered (Figures 2 and 3). Given the number of patients studied, there was sufficient statistical power ( $>80$ per cent) to detect a change of S/D ratio of 0.2 in either circulation had such a change been present.

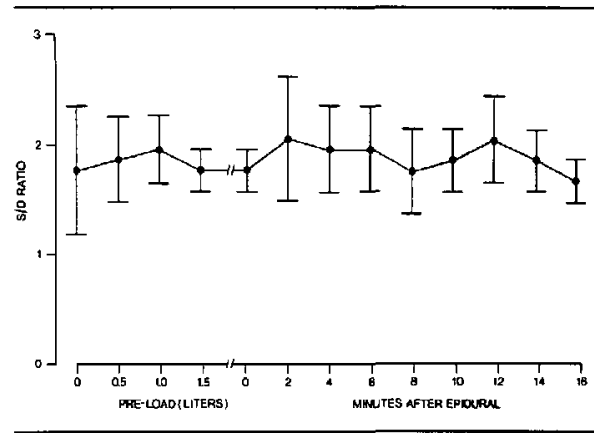

FIGURE 2 The effect of preload and epidural anaesthesia on uteroplacental S/D ratio (mean \pm SD) $P=$ NS.

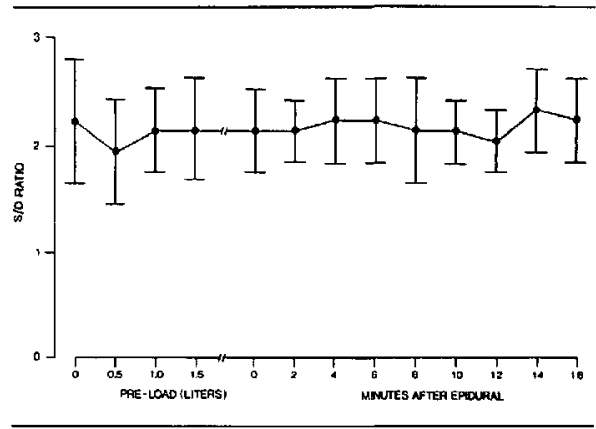

FGURE 3 The effect of preload and epidural anaesthesia on umbilical $S / D$ ratio (mean $\pm S D$ ) $P=N S$.

All infants had Apgar Scores $>8$ at five minutes and cord blood gases were within the normal range at birth.

\section{Discussion}

Doppler ultrasound has recently been introduced as a technique to assess fetal and maternal haemodynamic changes in the obstetric patient. ${ }^{4-6}$ The instrument detects changes in frequency of reflected ultrasound which is proportional to blood velocity. By analogy with other vascular beds, changes in the $S / D$ ratio are believed to reflect changes of vascular resistance in the uteroplacental and umbilical circulations. ${ }^{2,7} \mathrm{~A}$ reduction in S/D ratio would thus reflect reduced resistance which may improve blood flow while an increased S/D ratio may be detrimental. There are reports of the fetal haemodynamic effects of epidural anaesthesia in labour ${ }^{2,9}$ but we are aware of only one study that has assessed umbilical artery velocity changes in the patient receiving epidural anaesthesia for elective caesarean section. ${ }^{12}$ The effect of epidural 
anaesthesia in the patient prior to elective caesarean section may be different since the patient is not in pain, the uterus is not contracting, the hormonal environment is different and the dose of anaesthetic is greater.

It has been suggested that the high level of epidural blockade used for caesarean section may improve uterine blood flow. ${ }^{8,9}$ This may be due to a decrease in circulating catecholamines or to sympathetic blockade causing a reduction in vasoconstrictor tone. 9.11 Giles et al. showed that the S/D ratio was reduced following the epidural injection of $20-30 \mathrm{ml} 0.5$ per cent bupivacaine, but this effect did not appear to be significant until 30 minutes after establishment of anaesthesia. ${ }^{12}$ In most cases, delivery by elective caesarean section would have occurred in less than 30 minutes so we believe that improvement in the S/D ratio at this time would be of no therapeutic benefit. Our study showed that the $S / D$ ratio remained unchanged for up to 16 minutes using our anaesthetic technique. We stopped our observations at this time since there was sufficient anaesthesia to perform a caesarean section.

The small decrease in maternal blood pressure after administration of the anaesthetic we observed had no effect on either the uterine or umbilical flow velocity waveforms and was sufficiently small to be of no clinical significance.

The umbilical artery flow is an indicator of the fetal baemodynamic condition. Anaesthesia with $8 \mathrm{ml}$ of two per cent 2-chloroprocaine or 1.5 per cent lidocaine has been shown to be associated with a reduction of the umbilical S/D ratio in labouring patients. ${ }^{9,13}$ The mechanism for this change may be related to pain relief which is not a factor when considering epidurals for elective caesarean section. We have found no change in the S/D ratio up to 16 minutes, suggesting that the umbilical circulation remains unaltered by epidural anaesthesia within the usual time taken to establish the blockade. Further evidence for stability of the fetal circulation during epidural anaesthesia is the previous observation that fetal aortic and umbilical venous flow are unaltered during epidural anaesthesia prior to caesarean section. ${ }^{14}$ The fluid preload prior to anaesthesia had no effect on either the umbilical or uterine circulations.

Epinephrine was previously suggested to have a detrimental effect on the umbilical velocity in labouring patients when the S/D ratio was already abnormal. ${ }^{13}$ Our study shows no increase in the S/D ratio when epinephrine was given to patients with a normal umbilical artery flow velocity waveform.

We conclude that epidural anaesthesia for caesarean section using lidocaine with epinephrine has neither a direct nor indirect effect on the uterine and umbilical flow velocity waveforms and therefore under these circum- stances has neither a beneficial nor detrimental effect on fetal or uteroplacental blood flow.

\section{References}

I Shnider SM, Levinson G. Anaesthesia for cacsarean section. In: Anesthesia for Obstetrics. 2nd Edition. Shnider SM, Levinson G (Eds). Williams and Wilkins, Baltimore, 1987; 159-78.

2 Hollmen A, Jouppilla $R$, Jouppilla $P$ et al. Effect of extradural analgesia using bupivicaine and 2chloroprocaine on intervillous blood flow during normal labour. Br J Anaesth 1982; 54: 837-42.

3 Trudinger BJ, Giles WB, Cooke $C M$ et al. Fetal umbilical artery flow waveforms and placental resistance: clinical significance. Br J Obstet Gynaecol 1985; 92: 23-30.

4 Erskine RLA, Rirchie JWK. Umbilical antery blood flow characteristics in nonmal and growth retarded fetuses. Br J Obstet Gynaecol 1985; 92: 605-10.

5 Trudinger BJ, Cooke $C M$, Jones $L$ et al. A comparison of fetal heart monitoring and umbilical artery waveforms in the recognition of fetal compromise. Br J Obstet Gynaecol 1986; 92: 31-8.

6 Fleischer A, Schulman H, Farmakides $G$ et al. Uterine artery Doppler velocimetry in pregnant women with hypertension. Am J Obstet Gynecol 1986; 154: 806-13.

7 Olsen RM, Cooke JP. Human carotid artery diameter and flow by a non-invasive technique. Med Instrum 1975; 9 : 99-101.

8 Taylor JW, Burns PN, Woodcock JD et al. Blood flow in deep abdominal and pelvic vessels. Ultrasonic pulsedDoppler analysis. Radiology 1985; 154: 487-93.

9 Marx GF, Patel S, Berman JA et al. Umbilical blood flow velocity waveforms in different maternal positions and with epidural analgesia. Obstet Gynecol 1986; 68: 61-4.

10 Shnider SM, Abboud TK, Artal R et al. Maternal catecholamines decrease during labour after epidural anesthesia. Am J Obstet Gynecol 1983; 147: 13-5.

11 Jouppilla R, Puolakka J, Kauppilla et al. Maternal and umbilical cord plasma noradrenaline concentrations during labour with and without segmental extradural analgesia, and during caesarean section. Br $\mathrm{J}$ Anaesth 1986; 56: 251-5.

12 Giles WB, Lah FX, Trudinger BJ. The effect of epidural anaesthesia for caesarean section on matemal uterine and fetal umbilical artery arterial blood flow velocity waveforms. Br J Obstet Gynaecol 1987; 55-9.

13 Marx Gf, Schuss $M$, Anyaegbunam A et al. Effects of epidural block with lidocaine and lidocaine-epinephrine on umbilical blood flow velocity waveforms. Anesthesiology 1986; 65: A337.

14 Linblad A, Marsal $K$, Vernersson $E$ et al. Circulation during epidural analgesia for caesarean section. $\mathrm{Br}$ Med J 1984; 288: 1329-30. 
Résumé

Récemment, l'ultrasonographie (Doppler) a été utilisée pour évaluer les changements de la vitesse de perfusion sanguine dans les artères uterines et ombilicales. Il a été postulé que les changements dans le rapport de vitesse systolique us dyastolique (S/D) sont fonction des changements de résistance vasculaire placentaire. Nous avons utilisé cette technique pour mesurer les effets bénéfiques ou néfastes de l' anesthésie sous épidurale sur le volume sanguin placentaire. Le rapport SID des artères uterines et ombilicales de 12 gestantes ayant un accouchement par césarienne sous anesthésie épidurale fut mesure a l'aide d'ondes continues. Epinéphrine et lidocaine furent utilisées pour l'anesthésie. Ni la perfusion liquidienne interveineuse ni Tanesthésie épidurale ne causèrent de perturbations au niveau de l'artère utérine ou ombilicale. En conclusion, l'utilisation de cette technique tors l'anesthésie sous épidurale ne nous a pas permis de déceler d' effets bénéfiques ou néfastes sur la vitesse de perfusion sanguine lors de grossesses normales. 